\title{
Effects of Long-Afterglow Phosphorescent Pigments on Somatic Growth in Juvenile Goldlined Spinefoot Siganus guttatus
}

\author{
Chihiro Yamauchi ${ }^{1}$, Yuki Takeuchi ${ }^{1,2}$, Akihiro Takemura ${ }^{1, *}$ (i)
}

${ }^{1}$ University of the Ryukyus, Biology and Marine Science, Faculty of Science, Department of Chemistry, 1 Senbaru, Nishihara, Okinawa 903-0213, Japan.

${ }^{2}$ Okinawa Institute of Science and Technology Graduate School, 1919-1 Tancha, Onna, Okinawa 904-0495, Japan.

\section{Article History}

Received 18 November 2019

Accepted 23 December 2019

First Online 24 December 2019

\section{Corresponding Author}

Tel.: +81988958993

E-mail: takemura@sci.u-ryukyu.ac.jp

\section{Keywords}

Growth hormone

Growth rate

Insulin-like growth factor

LumiNova

\begin{abstract}
The purpose of the present study was to examine effectiveness of light emitted by long-afterglow phosphorescent pigments (LAPP) on the somatic growth of juvenile goldlined spinefoot. Comparison was done between juveniles in the aquarium with LAPP (exposure group) and those in the aquarium without LAPP (control group). When juveniles were reared under these conditions for more than 1 month, relative increase in somatic growth and average of specific growth rate of the juveniles (1-month-old, but not 9-month-old) in the exposure group were significantly higher $(P<0.05)$ than those in the control group. These results suggest that wavelength $(520 \mathrm{~nm})$ and period (at least 3 hours) of light emitted from LAPP after dusk stimulate the somatic growth of younger juveniles. The qPCR revealed that mRNA abundance of growth hormone $(\mathrm{GH})$ in the pituitary was significantly higher $(\mathrm{P}<0.05)$ in the control group than that in the exposure one, while an opposite effect was seen in that of insulin-like growth factor-I (IGF-I) in the liver. It is suggested that mRNA expression of IGF-I, but not GH, was stimulated by light from LAPP. It is concluded that LAPP becomes a useful tool for aquaculture promotion through stimulation of somatic growth in juveniles.
\end{abstract}

\section{Introduction}

Light is a complex of informative factors including color spectrum, intensity, and photoperiod, and is used as a periodical and reliable stimulus to control various physiological activities in relation to growth and reproduction in fish (Boeuf \& Le Bail, 1999). Many researchers have investigated the potential of manipulating photoperiodic regimes to stimulate somatic growth in various fish species, thereby enhancing aquaculture efficiency. Long-day conditions using fluorescent tubes have been found to accelerate the somatic growth of larvae and juveniles in some fish species (Gross, Roelofs, \& Fromm, 1965; Kissil, Lupatsch, Elizur, \& Zohar, 2001; Rad, Bozaoğlu, Ergene Gözükara, Karahan, \& Kurt, 2006; Shi, Zhang, Zhu, \& Liu, 2010;
Trippel \& Neil, 2003). Recently, light emitting diodes (LEDs) have been found to produce better results in promoting fish growth (Shin, Lee, \& Choi, 2012; Natalia Villamizar, Vera, Foulkes, \& Sánchez-Vázquez, 2014). They have several advantages over fluorescent tubes: they consume less power and allow aquaculturists to choose wavelengths of light optimized for increasing growth.

In the sapphire devil Chrysiptera cyanea, active vitellogenesis can be induced out of the reproductive season by rearing fish in aquaria covered with sheets of long-afterglow phosphorescent pigments (LAPP) (Bapary, Imamura, \& Takemura, 2012). These pigments emit visible wavelengths of light around $520 \mathrm{~nm}$ with exposure to UV rays and keep their brightness for more than 3 hours following removal of the UV light source 
(Nemoto, 2014). A similar result was obtained by mounting pellets containing LAPP on the pineal window of C. cyanea (Imamura, Bapary, Takeuchi, Hur, \& Takemura, 2014). These results indicate that fish can perceive wavelengths of light emitted by LAPP, and that it can be used to simulate long-day conditions, since vitellogenesis can also be induced in this species by rearing under long-day conditions created by fluorescent tubes (Bapary, Fainuulelei, \& Takemura, 2009; Bapary \& Takemura, 2010) and LEDs (Bapary, Amin, Takeuchi, \& Takemura, 2011).

A previous study revealed that somatic growth of juvenile goldlined spinefoot Siganus guttatus was accelerated under long-day conditions ( $L D=14: 10$ ) using green LED bulbs with a wavelength of $520 \mathrm{~nm}$ (Yamauchi \& Takemura, 2019). Based on this result, we hypothesized that LAPP could be used to stimulate somatic growth in this species because it has a high sensitivity to middle wavelengths of light (Yamauchi \& Takemura, 2019). The aim of this study was to examine whether LAPP can accelerate somatic growth in juvenile goldlined spinefoot and whether age of its juveniles is related to acceleration of somatic growth with LAPP. To investigate this question, we reared 1-month-old and 9month-old goldlined spinefoot in aquaria with or without a covering of LAPP sheets and compared changes in somatic growth between the two conditions. In addition, the mRNA abundance of growth hormone $(\mathrm{GH})$ in the pituitary and insulin-like growth factor-I (IGFI) in the liver of goldlined spinefoot juveniles was measured using real-time quantitative polymerase chain reaction ( $q P C R$ ).

\section{Materials and Methods}

\section{Animals}

Goldlined spinefoot fry ranging from 0.08 to $0.15 \mathrm{~g}$ in body weight (BW) were collected from mangrove swamps in Northern Okinawa, Japan. Collection was performed with hand nets at low tide during the new moon in July and August. Fry were brought to Sesoko Station, Tropical Biosphere Research Center, University of the Ryukyus, Okinawa, Japan $\left(26^{\circ} 38^{\prime} \mathrm{N}, 127^{\circ} 51^{\prime} \mathrm{E}\right)$, and kept in indoor circular concrete tanks (10 metric ton capacity) with running seawater and gentle aeration under a natural photoperiod (ranging from $10.31 \mathrm{~h}$ to $13.37 \mathrm{~h}$ ) and water temperature (ranging $19.1 \pm 0.22{ }^{\circ} \mathrm{C}$ in February to $29.5 \pm 0.13^{\circ} \mathrm{C}$ in July). Commercial marine fish pellets (Pure Gold EP1 or EP2; Nisshin-Marubeni, Tokyo, Japan) were given to fish once a day at $1000 \mathrm{~h}$ until the start of the experimental period.

All experiments were conducted in compliance with the guidelines of the Animal Care and Use Committee established by the University of the Ryukyus and regulations for the care and use of laboratory animals in Japan.

\section{Rearing fish using long-afterglow phosphorescent pigments}

Sheets containing LAPP (LumiNova, G-300M) used in the present study were purchased from Nemoto Lumi-Materials (Tokyo, Japan). LAPP sheets were attached to styrene foam boards, which were fit to the glass surface of each aquarium. One-month-old juveniles (22 individuals per aquarium), ranging from $1.71 \pm 0.04 \mathrm{~g}$ in BW and from $4.7 \pm 0.04 \mathrm{~cm}$ in total length (TL), were housed in two outdoor aquaria (60-L capacity) with running seawater and aeration; one aquarium (exposure group) was covered with LAPP sheets attached to styrene foam boards, while the other aquarium (control group) was covered with styrene foam boards without LAPP sheets (Figure 1). Fish were reared under these conditions for 1 month. The same experiment was carried out using 9-month-old fish (12 individuals per aquarium), ranging from $21.33 \pm 2.03 \mathrm{~g}$ in BW and from $10.2 \pm 0.32 \mathrm{~cm}$ in TL, which were reared for 2 months. According to the previous report (Nakama, 2010), fish were fed Pure Gold EP1 and EP2 (5\% of BW) once a day at $1000 \mathrm{~h}$ in both experiments. The abovementioned BW and TL were expressed as the mean \pm standard error of the mean.

After a 1-week acclimatization period, all fish were removed from aquaria and anesthetized with $0.01 \% 2$ phenoxyethanol (Kanto Chemical, Tokyo, Japan) so that initial BW and TL could be measured. The BW and TL of all fish in aquaria were recorded every 2 weeks after the initial measurement, and a ratio of growth to the initial BW and TL was calculated. It is unlikely that our sampling frequency has to have a negative impact on growth performance of this species because a steady increase in somatic growth was recorded using the same experimental regime(Yamauchi \& Takemura, 2019). Growth parameters of juveniles were calculated as follows:

\section{Specific growth rate (SGR, \% day $\left.{ }^{-1}\right)$; \\ Condition factor (CF, \%); $\left[\left(\ln W_{\mathrm{f}}-\ln W_{\mathrm{i}}\right) / t\right] \times 100$ (body weight / total length $^{3}$ ) $\times 100$}

Where $W_{\mathrm{f}}, W_{\mathrm{i}}$, and $t$ are the final weight, initial weight, and time period (day), respectively.

The similar experiment was carried out for analysis of growth-related gene mRNA expressions. The 9month-old juveniles (10 individuals per aquarium) were reared in two indoor aquaria (60-L capacity), which don't affect any light from outside, with running seawater and aeration for 1 week. The light condition was 12-hour light and 12-hour darkness. Fish were anesthetized at $2100 \mathrm{~h}$ sacrificed by decapitation according to the previous report (Yamauchi \& Takemura, 2019). The pituitary and liver were removed from each fish and immersed in TriPure Isolation 


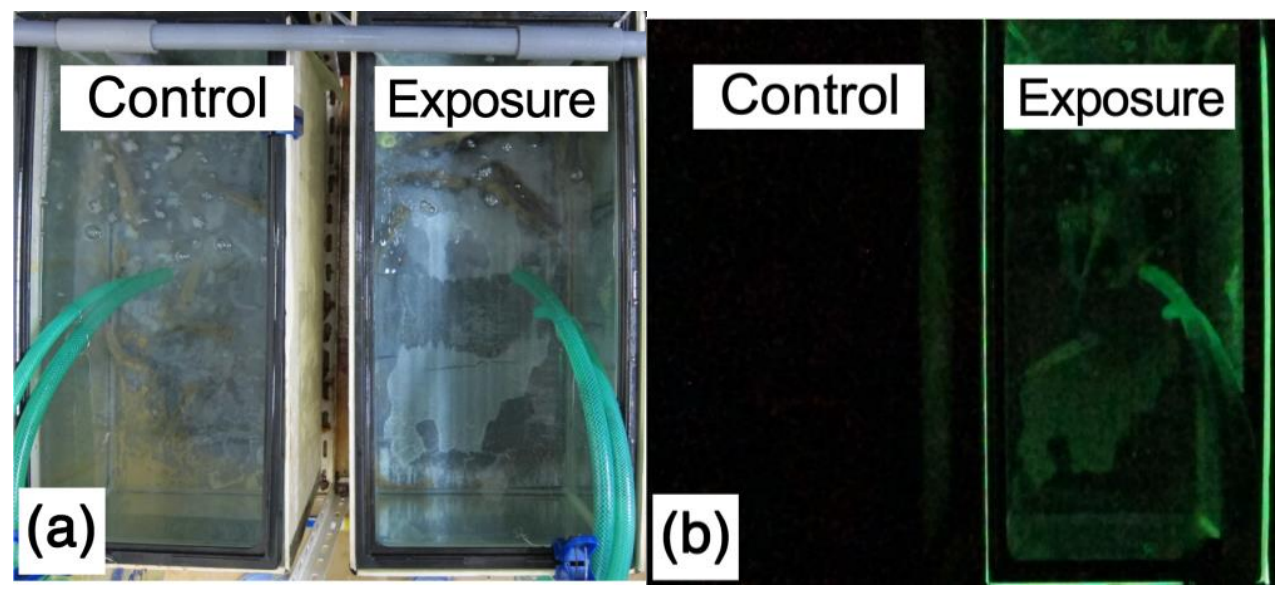

Figure 1. Comparison of brightness between aquariums in the absence (Control) and presence (Exposure) of long-afterglow phosphorescent pigments. Left (a) and right (b) photos of aquariums were taken during the photophase and scotophase, respectively.

Reagent (Roche Molecular Systems, Pleasanton, CA, USA) and held at $-80^{\circ} \mathrm{C}$ until RNA extraction could be performed.

\section{Measurement of GH and IGF-I mRNA expression}

Total RNA was extracted from frozen samples using Tripure Isolation Reagent according to the manufacturer's protocol and treated with recombinant DNase I (RNase-free; Takara Bio, Otsu, Japan) to avoid genomic DNA contamination. First-strand cDNA was synthesized from $500 \mathrm{ng}$ of total RNA using the PrimeScript RT reagent kit (Perfect Real Time; Takara Bio) according to the manufacturer's protocol.

The nucleotide sequences of GH, IGF-I, and $\beta$-actin (GenBank accession nos. AB031298, AY198184, and $A B 643460$, respectively) were previously determined (Ayson et al., 2000). The gene-specific primers of $\mathrm{GH}$, IGF-I, and $\beta$-actin for qPCR were shown in Table 1. Each PCR was conducted in a final volume of $10 \mu$ l containing $5 \mu$ l of SYBR Premix Ex Taq II (Takara Bio), $0.2 \mu$ l each of forward and reverse primers, $3.8 \mu \mathrm{l}$ of nuclease-free water, and $0.8 \mu \mathrm{l}$ of cDNA template. The qPCR cycling conditions were $95^{\circ} \mathrm{C}$ for $3 \mathrm{~min}, 35$ cycles of $95^{\circ} \mathrm{C}$ for 30 $\mathrm{s}, 55^{\circ} \mathrm{C}$ for $30 \mathrm{~s}$, and $72^{\circ} \mathrm{C}$ for $30 \mathrm{~s}$, followed by $95^{\circ} \mathrm{C}$ for $15 \mathrm{~s}, 60^{\circ} \mathrm{C}$ for $15 \mathrm{~s}$, and $95^{\circ} \mathrm{C}$ for $5 \mathrm{~s}$. The relative mRNA expression levels of $\mathrm{GH}$ and $\beta$-actin genes were calculated using the ${ }^{\Delta \Delta} \mathrm{Ct}$ method, and $\beta$-actin expression was used to normalize transcript levels. Measurement of each gene was performed in duplicate.

\section{Statistical analysis}

All data were expressed as the mean \pm standard error of the mean. Student's $t$-test was applied to compare changes in BW, TL, SGR, and CF between the exposure and control groups. The data of GH and IGF-I mRNA abundance in the pituitary and in the liver were unequal variance by homogeneity checking. Thus, the effect of the LAPP sheets on GH and IGF-I mRNA abundance was measured using Welch's $t$-test. The threshold for significance was set at $\mathrm{P}<0.05$ for all tests.

\section{Results}

\section{Effect of LAPP on changes in BW and TL in juveniles}

One-month-old juveniles were reared in aquaria with (exposure group) or without (control group) LAPP sheets for 1 month. No mortality was observed in fish during the experiment. The TL and BW of 1-month-old juveniles steadily increased in both groups (Fig. 2a and b). There were measurable differences in TL and BW between the two groups 2 weeks after the initiation of the experiment; $T L$ and $B W$ of the exposure group were significantly higher $(P<0.05)$ than those of the control group. Growth was still measurably higher $(P<0.01)$ in the exposure group 4 weeks after the initiation of the experiment. SGR was also significantly higher $(P<0.05)$ in the exposing group than the control one (Table 2).

The same experiment was carried out using 9month-old fish. Steady increases in TL and BW were recorded in both exposure and control groups. Somatic growth was slightly higher in the control group, but the difference between the two groups was not significant (Fig. 3). There was no difference in SGR between two groups (Table 2 ).

\section{mRNA expression of GH and IGF-I}

The effect of light emitted by LAPP on the mRNA abundance of GH in the pituitaries and IGF-I in the livers of 9-month-old fish was examined using qPCR (Fig. 4). We found that the abundance of GH mRNA in the pituitaries of the control group was approximately 2.5 times higher than in the exposure group. An opposite 
Table 1. Primer set sequences used in the present study

\begin{tabular}{|c|c|}
\hline Primer & Sequence* \\
\hline $\mathrm{GH}-\mathrm{F}$ & 5'-TCC ACC AGG TTG CTC AGA GA-3' \\
\hline $\mathrm{GH}-\mathrm{R}$ & 5'-CCG GAT GTA ATC GGA GTT GC-3' \\
\hline IGF-1-F & 5'-GCT GCA GTT TGT GTG TGG AG-3' \\
\hline IGF-1-R & 5'-CTT TGG AAG CAG CAC TCG TC-3' \\
\hline$\beta$-actin- $F$ & 5'-TAC CAC CAT GTA CCC TGG CAT C-3' \\
\hline$\beta$-actin-R & 5'-TAC GCT CAG GTG GAG CAA TGA-3' \\
\hline
\end{tabular}

*Primers were designed and used in the previous report (Ayson \& Takemura, 2006).
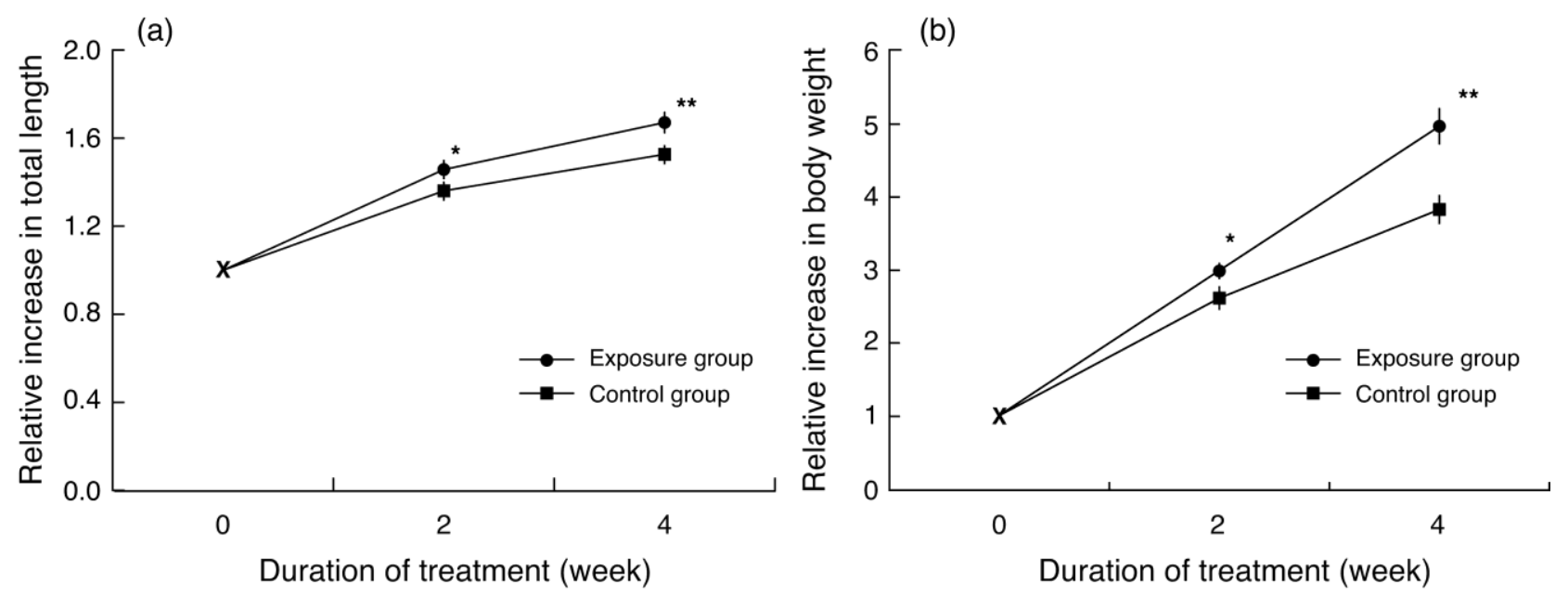

Figure 2. Effect of long-afterglow phosphorescent pigments on relative increases in total length (a) and body weight (b) of the juvenile goldlined spinefoot. One-month-old juveniles were reared in aquarium in the presence and absence of long-afterglow phosphorescent pigments for 4 weeks and total length (a) and body weight (b) were recorded every 2 weeks. Relative increases in total length and body weight for initial values were calculated. Data were expressed as means \pm standard error of the mean (SEM). Asterisks * and ${ }^{* *}$ indicate statistical difference at $\mathrm{P}<0.05$ and $\mathrm{P}<0.01$, respectively.

Table 2. Effect of LumiNova on growth performance of juvenile goldlined spinefoot

\begin{tabular}{lcc}
\hline \multirow{2}{*}{ Parameters } & \multicolumn{2}{c}{ Long-afterglow phosphorescent pigments* } \\
\cline { 2 - 3 } & Presence & Absence \\
\hline 1-month-old juveniles** & & $1.70 \pm 0.06^{\mathrm{a}}$ \\
Initial body weight (g) & $1.71 \pm 0.52^{\mathrm{a}}$ & $6.49 \pm 0.31^{\mathrm{a}}$ \\
Final body weight (g) & $8.42 \pm 0.37^{\mathrm{b}}$ & $4.39 \pm 0.16^{\mathrm{a}}$ \\
SGR (\% day ${ }^{-1}$ & $5.25 \pm 0.15^{\mathrm{b}}$ & $1.70 \pm 0.03^{\mathrm{a}}$ \\
CF (\%) & $1.71 \pm 0.02^{\mathrm{a}}$ & \\
& & $21.33 \pm 2.03^{\mathrm{a}}$ \\
9-month-old juveniles** & & $47.05 \pm 4.80^{\mathrm{a}}$ \\
Initial body weight (g) & $21.33 \pm 2.03^{\mathrm{a}}$ & $1.32 \pm 0.17^{\mathrm{a}}$ \\
Final body weight (g) & $39.85 \pm 3.40^{\mathrm{a}}$ & $1.95 \pm 0.05^{\mathrm{a}}$ \\
SGR (\% day ${ }^{-1}$ ) & $1.06 \pm 0.16^{\mathrm{a}}$ & \\
CF (\%) & $1.89 \pm 0.04^{\mathrm{a}}$ & \\
\hline
\end{tabular}

*Different letters indicate statistically significant differences $(P<0.05)$.

**One-month-old and nine-month-old juveniles were reared for 4 and 8 weeks, respectively 
(a)

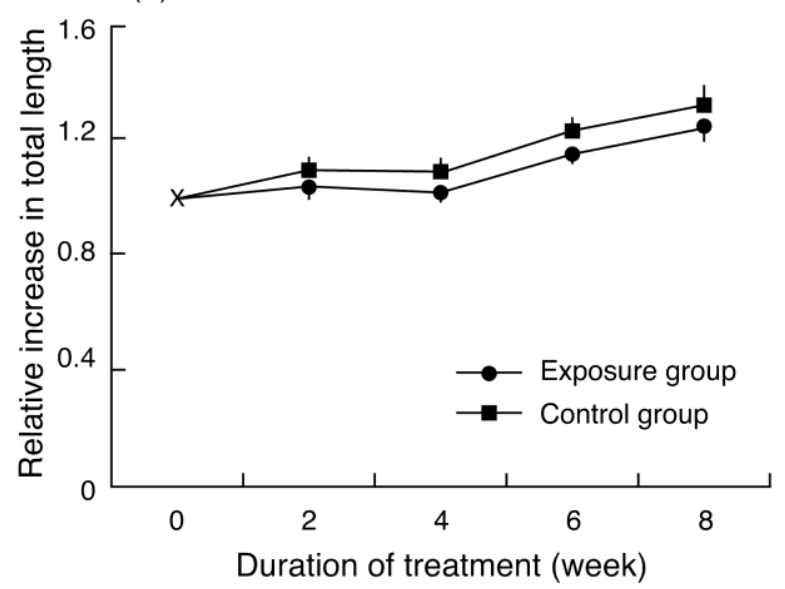

(b)

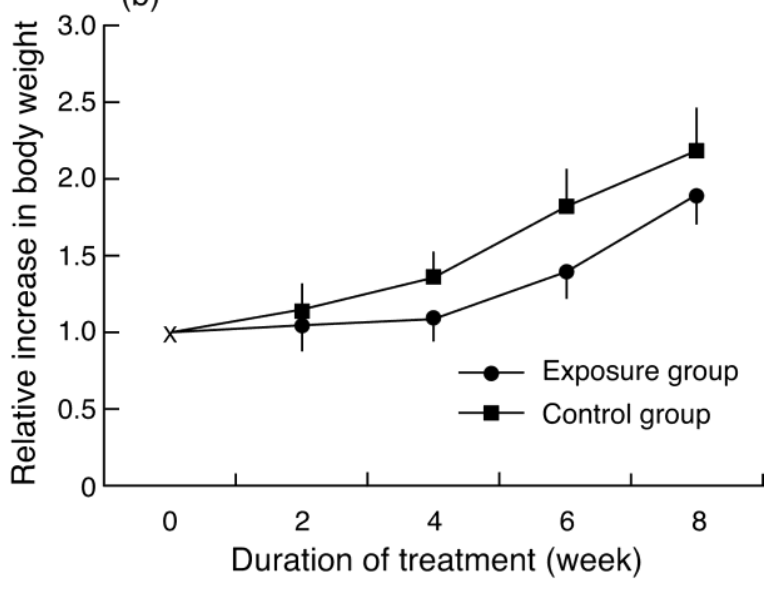

Figure 3. Effect of long-afterglow phosphorescent pigments on relative increases in total length (a) and body weight (b) of the juvenile goldlined spinefoot. in the presence and absence of long-afterglow phosphorescent pigments for 8 weeks and total length (a) and body weight (b) were recorded every 2 weeks. Relative increases in total length and body weight for initial values were calculated. Data were expressed as means \pm standard error of the mean (SEM).
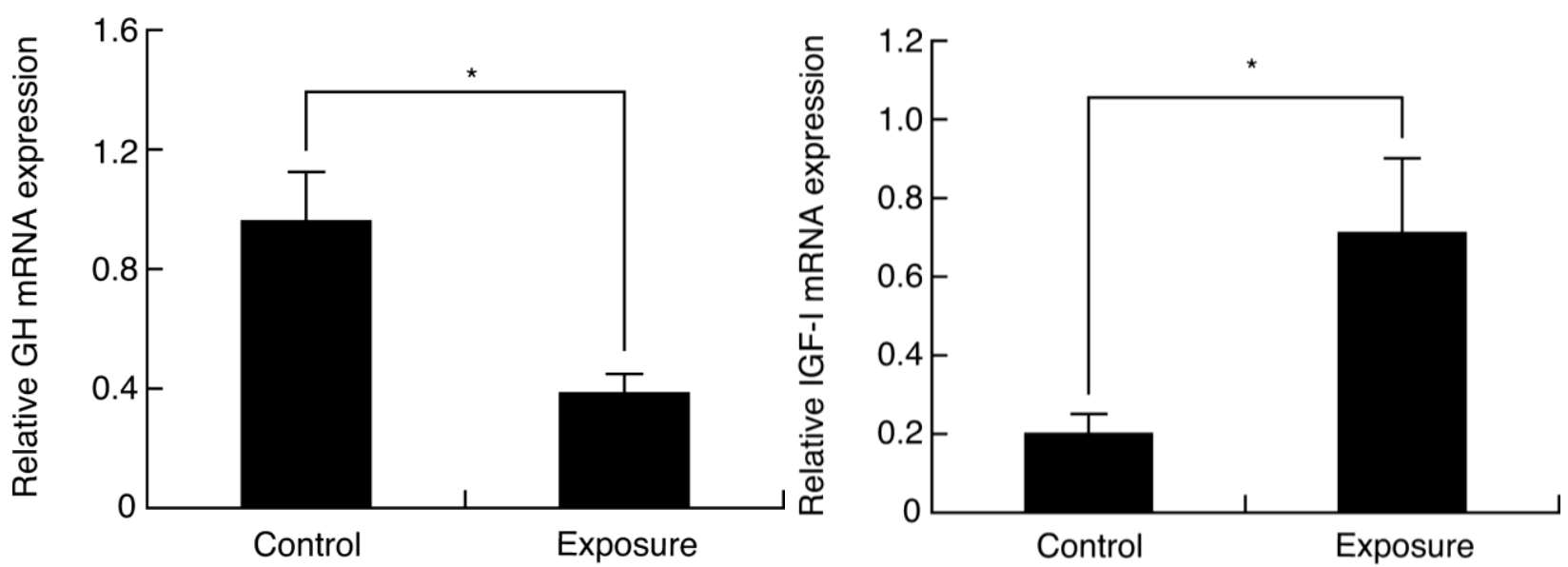

Figure 4. Effect of long-afterglow phosphorescent pigments on mRNA abundance of growth hormone (GH) in the pituitary and insulin-like growth factor-I (IGF-I) in the liver of the young goldlined spinefoot. Nine-month-old fish were reared in aquarium in the presence and absence of long-afterglow phosphorescent pigments for 8 weeks. Following total RNA isolation and reversetranscription, mRNA abundance of GH in each sample was measured real-time qPCR, normalized against mRNA abundance of $ß$ actin, and then averaged. Values are expressed as means \pm standard error of the mean (SEM). Asterisks represents statistical difference at $\mathrm{P}<0.05$.

expression pattern was observed in the abundance of IGF-I mRNA in the livers; approximately 5.0 times higher expression of IGF-I mRNA was recorded in the exposure group. Difference in the mRNA abundance of $\mathrm{GH}$ and IGF-I between two groups was significant $(\mathrm{P}<0.05)$.

\section{Discussion}

Under the conditions of this study, 1-month-old juveniles in the exposure group grew faster than those in the control group. Since the difference between these two groups was the presence or absence of LAPP in rearing conditions, it seems likely that the light emitted by pigments in the sheets played a role in stimulating the somatic growth of juvenile goldlined spinefoot. This effect seems to be restricted to younger fish; there was a significant difference in somatic growth between the two groups of 1-month-old juveniles, but no difference between the groups of 9-month-olds.

There are at least two possible mechanisms by which LAPP could stimulate the somatic growth of juvenile goldlined spinefoots. The first possibility is that the wavelengths of light emitted by LAPP inherently stimulate somatic growth in this species. This idea is supported by the results of a previous study, in which 1and 9-month-old goldlined spinefoot juveniles were reared for 4 weeks under red $(627 \mathrm{~nm})$, green $(520 \mathrm{~nm})$, or blue ( $455 \mathrm{~nm}$ ) LED lights; the highest rate of somatic 
growth was obtained in 1-month-old juveniles exposed to green LED lights (Yamauchi \& Takemura, 2019). Similar effects have been found in the yellowtail clownfish Amphiprion clarkia (Shin et al., 2012) and the barfin flounder Verasper moseri (Takahashi et al., 2016) exposed to green LED lights at $530 \mathrm{~nm}(\mathrm{LD}=12: 12)$ and $518 \mathrm{~nm}$ (LD = 10.5:13.5), respectively. Color sensitivity and perception may differ among species; larvae of the European sea bass Dicentrarchus larbrax reared under blue lights showed more growth at 40 days after hatching than those exposed to red light (Villamizar, García-Alcazar, \& Sánchez-Vázquez, 2009). In addition, higher reproductive performance was recorded in the Nile tilapia Oreochromis niloticus reared under blue rather than white light (Volpato, Duarte, \& Luchiari, 2004).

A second possibility is that growth is stimulated by the prolonged light phase caused by the use of LAPP. LAPP continues to emit light for several hours after sunset, although luminance decay with time (from 1000 to $10 \mathrm{mcd} / \mathrm{m}^{2}$ within approximately 3 hours) (Nemoto, 2014). It is likely that fish are placed under long-day conditions because steady growth of this species did not alter under low light intensity $(0.1 \%$ of natural sunlight at culmination) (Yamauchi \& Takemura, 2019). Previous results have shown that rearing goldlined spinefoot under long-day ( $L D=14: 10$ ) or constant light conditions with fluorescent bulbs enhanced the somatic growth of juveniles (Yamauchi \& Takemura, 2019). The effect of day-length on somatic growth has been evaluated in other fish species as well (Biswas \& Takii, 2016; Fülberth, Moran, Jarlbæk, \& Støttrup, 2009; Ginés, Afonso, Argüello, Zamorano, \& López, 2004; Petit, Beauchaud, Attia, \& Buisson, 2003; Villamizar et al., 2009). Long-day or constant light during rearing enhanced somatic growth of larval European sea bass (Villamizar et al., 2009), juvenile striped knifejaw Oplegnathus fasciatus (Biswas et al., 2008), and immature gilthead sea bream Sparus aurata (Ginés et al., 2004). It was mentioned that longer photoperiod (e.g. constant light) leads prolongation foraging activity and feeding time in diurnal species, and, consequently, alternation of hormonal control in relation to metabolic regulation (Biswas, Seoka, Tanaka, Takii, \& Kumai, 2006; Petit et al., 2003). Since goldlined spinefoot is also a diurnal species, similar efficiency on feeding activity may occur under long-day conditions by LAPP. In addition, it may be worth noting that a photoinducible phase appears in a circadian manner in the sapphire devil, which is a tropical damselfish with preference of long-day conditions; when the fish were reared under short-day with a light pulse between zeitgeber time (ZT)12 and ZT13, vitellogenic oocytes could be observed in an ovary (Takeuchi et al., 2015).

It is unlikely that light intensity plays a crucial role in enhancing the somatic growth of juvenile goldlined spinefoot because steady growth of this species did not alter under low light intensity $(0.1 \%$ of natural sunlight at culmination; $34.2 \mathrm{~lx}$ ) (Yamauchi \& Takemura, 2019). Compared with goldlined spinefoot, on the other hand, relatively strong light intensity seems to be needed; weight gain and specific growth rate can be stimulated by light intensities ranging from 320 to $1150 \mathrm{~lx}$ in the orange-spotted grouper Epinepherus coioides (Wang, Cheng, Liu, Yan, \& Long, 2013) and of 400 Ix in the blunt snout bream Megalobrama amblycephala (Tian, Zhang, Xu, Wang, \& Liu, 2015). In this context, it may be worth mentioning that the goldlined spinefoot is capable of sensing even very weak light (Takeuchi et al., 2018) because melatonin synthesis in the pineal organ decreased after exposing to moonlight (Takemura, Ueda, Hiyakawa, \& Nikaido, 2006).

Exposure to illumination from LAPP is likely to stimulate the hormonal network related to somatic growth of the goldlined spinefoot. It has been reported that exposing barfin flounder to green LED lights for 4 weeks results in increased plasma levels of IGF-I and insulin, transcript levels of proopiomelanocortin (POMC)-C in the brain, and transcript levels of POMC-B and $-C$ in the pituitary, compared with fish exposed to red LED lights (Takahashi et al., 2016). Green light signals may be perceived by photoreceptors and transmitted to the hypothalamus, which regulates the endocrine system as it relates to feeding behavior (Takahashi et al., 2016). Although the brain and pituitary hormones mentioned above were not measured in the present study, the abovementioned finding (Takeuchi et al., 2018) suggests that this species is capable of adapting to moonlight conditions and of transducing green light stimuli to the hypothalamus. In the 9-month-old fish used in the present study, transcript levels of $\mathrm{GH}$ in the pituitary were lower in the exposure group than in the control group, while an opposite effect of LAPP on IGF-I in the liver was observed. It is suggested that IGF-I, but not $\mathrm{GH}$, is positively related to somatic growth in the goldlined spinefoot. Similarly, no significant difference was observed in the mRNA abundance of $\mathrm{GH}$ in the pituitary of the barfin flounder between fish exposed to blue, green, or red LED lights for 4 weeks, suggesting that $\mathrm{GH}$ in the pituitary does not function as a driver of IGF-I production in and release from the liver (Takahashi et al., 2016). Similar to the present study, we confirmed a day-low and night-high expression profile of GH mRNA expression in the pituitary and an opposite expression profile of IGF-I mRNA in the liver of 11-month-old goldlined spinefoot, when fish were reared under longday conditions (Yamauchi \& Takemura, 2019). This may be attributed to long-term exposure of fish to particular wavelengths of light.

In conclusion, somatic growth of goldlined spinefoot juveniles, and potentially of other fish species, can be stimulated using LAPP. Its effectiveness is maximized in fish ranging from newly hatched larvae to juveniles by the concatenation of wavelength (green light) and long-day. Compared with other light sources, LAPP has advantages in weather and light fastness, salt 
and chemical tolerance, and no electric energy consumption. Therefore, it can be introduced as a potentially useful aquaculture tool for promoting somatic growth.

\section{Acknowledgements}

We gratefully thank staff of Sesoko Station, Tropical Biosphere Research Center, University of the Ryukyus, Okinawa, Japan, for use of facilities. This study was supported in part by a Grant-in-Aid for Challenging Exploratory Research (Grant Number 25660170) from the Japan Society for the Promotion of Science (JSPS) to AT.

\section{References}

Ayson, F. G., De Jesus, E. G. T., Amemiya, Y., Moriyama, S., Hirano, T., \& Kawauchi, H. (2000). Isolation, cDNA cloning, and growth promoting activity of rabbitfish (Siganus guttatus) growth hormone. General and Comparative Endocrinology, 117(2), 251-259. https://doi.org/10.1006/gcen.1999.7409

Ayson, F. G., \& Takemura, A. (2006). Daily expression patterns for mRNAs of GH, PRL, SL, IGF-I and IGF-II in juvenile rabbitfish, Siganus guttatus, during 24-h light and dark cycles. General and Comparative Endocrinology, 149(3), 261-268. https://doi.org/10.1016/j.ygcen.2006.06.006

Bapary, M. A. J., Amin, M. N., Takeuchi, Y., \& Takemura, A. (2011). The stimulatory effects of long wavelengths of light on the ovarian development in the tropical damselfish, Chrysiptera cyanea. Aquaculture, 314(1-4), 188-192.

https://doi.org/10.1016/j.aquaculture.2011.02.006

Bapary, M. A. J., Fainuulelei, P., \& Takemura, A. (2009). Environmental control of gonadal development in the tropical damselfish Chrysiptera cyanea. Marine Biology Research, 5(5), 462-469. https://doi.org/10.1080/17451000802644722

Bapary, M. A. J., Imamura, S., \& Takemura, A. (2012). Longafterglow phosphorescent pigment is a potent tool for manipulation of reproductive performance in the tropical damselfish Chrysiptera cyanea. Fisheries Science, 78(2), 337-342.

https://doi.org/10.1007/s12562-011-0448-2

Bapary, M. A. J., \& Takemura, A. (2010). Effect of temperature and photoperiod on the reproductive condition and performance of a tropical damselfish Chrysiptera cyanea during different phases of the reproductive season. Fisheries Science, 76(5), 769-776. https://doi.org/10.1007/s12562-010-0272-0

Biswas, A. K., Seoka, M., Tanaka, Y., Takii, K., \& Kumai, H. (2006). Effect of photoperiod manipulation on the growth performance and stress response of juvenile red sea bream (Pagrus major). Aquaculture, 258(1-4), 350356. https://doi.org/10.1016/j.aquaculture.2006.03.048

Biswas, A. K., Seoka, M., Ueno, K., Yong, A. S. K., Biswas, B. K., Kim, Y. S., ... Kumai, H. (2008). Growth performance and physiological responses in striped knifejaw, Oplegnathus fasciatus, held under different photoperiods. Aquaculture, 279(1-4), 42-46. https://doi.org/10.1016/j.aquaculture.2008.04.007
Biswas, A., \& Takii, K. (2016). Effects of light intensity on the growth performance and stress response in striped knifejaw, (Oplegnathus fasciatus). Journal of the World Aquaculture Society, 47(6), 806-811. https://doi.org/10.1111/jwas.12313

Boeuf, G., \& Le Bail, P. Y. (1999). Does light have an influence on fish growth? Aquaculture, 177(1-4), 129-152. https://doi.org/10.1016/S0044-8486(99)00074-5

Fülberth, M., Moran, D., Jarlbæk, H., \& Støttrup, J. G. (2009). Growth of juvenile Atlantic cod Gadus morhua in landbased recirculation systems: Effects of feeding regime, photoperiod and diet. Aquaculture, 292(3), 225-231. https://doi.org/10.1016/j.aquaculture.2009.04.028

Ginés, R., Afonso, J. M., Argüello, A., Zamorano, M. J., \& López, J. L. (2004). The effects of long-day photoperiod on growth, body composition and skin colour in immature gilthead sea bream (Sparus aurata L.). Aquaculture Research, 35(13), 1207-1212. https://doi.org/10.1111/j.1365-2109.2004.01126.x

Gross, W. L., Roelofs, E. W., \& Fromm, P. O. (1965). Influence of photoperiod on growth of green sunfish, Lepomis cyanellus. Journal of Fisheries Research Board Canada, 22(6), 1379-1386. https://doi.org/10.1139/f65-121

Imamura, S., Bapary, M. A. J., Takeuchi, Y., Hur, S. P., \& Takemura, A. (2014). Stimulation of ovarian development in a tropical damselfish by prolonged photoperiod using pellets containing long-afterglow phosphorescent pigment. Fisheries and Aquatic Sciences, 17(2), 223-227. https://doi.org/10.5657/FAS.2014.0223

Kissil, G. W., Lupatsch, I., Elizur, A., \& Zohar, Y. (2001). Long photoperiod delayed spawning and increased somatic growth in gilthead seabream (Sparus aurata). Aquaculture, 200(3-4), 363-379. https://doi.org/10.1016/S0044-8486(01)00527-0

Nemoto. (2014). Retrieved from https://www.nemoto.co.jp/nlm/qa/ggllseries?lang=en

Petit, G., Beauchaud, M., Attia, J., \& Buisson, B. (2003). Food intake and growth of largemouth bass (Micropterus salmoides) held under alternated light/dark cycle (12L:12D) or exposed to continuous light. Aquaculture, 228(1-4), 397-401. https://doi.org/10.1016/S00448486(03)00315-6

Rad, F., Bozaoğlu, S., Ergene Gözükara, S., Karahan, A., \& Kurt, G. (2006). Effects of different long-day photoperiods on somatic growth and gonadal development in Nile tilapia (Oreochromis niloticus L.). Aquaculture, 255(1-4), 292 300. https://doi.org/10.1016/j.aquaculture.2005.11.028

Shi, Y., Zhang, G., Zhu, Y., \& Liu, J. (2010). Effects of photoperiod, temperature, and salinity on growth and survival of obscure puffer Takifugu obscurus larvae. Aquaculture, 309(1-4), 103-108. https://doi.org/10.1016/j.aquaculture.2010.09.004

Shin, H. S., Lee, J., \& Choi, C. Y. (2012). Effects of LED light spectra on the growth of the yellowtail clownfish Amphiprion clarkii. Fisheries Science, 78(3), 549-556. https://doi.org/10.1007/s12562-012-0482-8

Takahashi, A., Kasagi, S., Murakami, N., Furufuji, S., Kikuchi, S., Mizusawa, K., \& Andoh, T. (2016). Chronic effects of light irradiated from LED on the growth performance and endocrine properties of barfin flounder Verasper moseri. General and Comparative Endocrinology, 232, 101-108. https://doi.org/10.1016/j.ygcen.2016.01.008

Takemura, A., Ueda, S., Hiyakawa, N., \& Nikaido, Y. (2006). A direct influence of moonlight intensity on changes in 
melatonin production by cultured pineal glands of the golden rabbitfish, Siganus guttatus. Journal of Pineal Research, 40(3), 236-241. https://doi.org/10.1111/j.1600-079X.2005.00306.x

Takeuchi, Y., Hada, N., Imamura, S., Hur, S.-P. P., Bouchekioua, S., \& Takemura, A. (2015). Existence of a photoinducible phase for ovarian development and photoperiod-related alteration of clock gene expression in a damselfish. Comparative Biochemistry and Physiology A, 188, 32-39. https://doi.org/10.1016/j.cbpa.2015.06.010

Takeuchi, Y., Kabutomori, R., Yamauchi, C., Miyagi, H., Takemura, A., Okano, K., \& Okano, T. (2018). Moonlight controls lunar-phase-dependency and regular oscillation of clock gene expressions in a lunar-synchronized spawner fish, Goldlined spinefoot. Scientific Reports, 8(1). https://doi.org/10.1038/s41598-018-24538-1

Tian, H. Y., Zhang, D. D., Xu, C., Wang, F., \& Liu, W. Bin. (2015). Effects of light intensity on growth, immune responses, antioxidant capability and disease resistance of juvenile blunt snout bream Megalobrama amblycephala. Fish and Shellfish Immunology, 47(2), 674-680. https://doi.org/10.1016/j.fsi.2015.08.022

Trippel, E. A., \& Neil, S. R. E. (2003). Effects of photoperiod and light intensity on growth and activity of juvenile haddock (Melanogrammus aeglefinus). Aquaculture, 217(1-4), 633-645.

https://doi.org/10.1016/S0044-8486(02)00198-9
Villamizar, N., García-Alcazar, A., \& Sánchez-Vázquez, F. J. (2009). Effect of light spectrum and photoperiod on the growth, development and survival of European sea bass (Dicentrarchus labrax) larvae. Aquaculture, 292(1-2), 80-86.

https://doi.org/10.1016/j.aquaculture.2009.03.045

Villamizar, Natalia, Vera, L. M., Foulkes, N. S., \& SánchezVázquez, F. J. (2014). Effect of lighting conditions on zebrafish growth and development. Zebrafish, 11(2), 173-181. https://doi.org/10.1089/zeb.2013.0926

Volpato, G. L., Duarte, C. R. A., \& Luchiari, A. C. (2004). Environmental color affects Nile tilapia reproduction. Brazilian Journal of Medical and Biological Research, 37(4), 479-483.

https://doi.org/10.1590/S0100-879X2004000400004

Wang, T., Cheng, Y., Liu, Z., Yan, S., \& Long, X. (2013). Effects of light intensity on growth, immune response, plasma cortisol and fatty acid composition of juvenile Epinephelus coioides reared in artificial seawater. Aquaculture, 414-415, 135-139.

https://doi.org/10.1016/j.aquaculture.2013.08.004

Yamauchi, C., \& Takemura, A. (2019). Effects of photic conditions on growth performance in juveniles of the goldlined spinefoot, Siganus guttatus (Bloch, 1787). Turkish Journal of Fisheries and Aquatic Sciences, 19(11), 915-922.

https://doi.org/10.4194/1303-2712-v19_11_03 